\title{
Crónica de eventos anunciados
}

Ana Isabel Campillo Corrales Universidad de Sonora Departamento de Bellas Artes aicampic@capomo.uson.mx
Con la llegada de Septiembre y sobre todo con nuestra habitual e infundada creencia de que el calor ya se va, los hermosillenses salimos de nuestras casas para asistir a los ya múltiples eventos que se organizan en la ciudad por diversas instancias. La Universidad de Sonora no se queda atrás. Justamente en estas fechas la diversidad de proyectos artísticos fructifican y se difunden no sólo dentro del campus, sino que se comparten con la comunidad. El decimosegundo Festival Internacional de Teatro Universitario generó expectativas que se cumplieron en su totalidad. Se realizaron talleres no sólo para nuestros estudiantes sino para egresados, que de esta manera están en contacto con su alma mater y permite un intercambio importante entre la teoría y la práctica profesional. La visita de la Compañía Nacional de Teatro, después de 38 años de ausencia fue un logro trascendente. Las primeras actrices brindaron una charla con estudiantes e invitados en el Foro de Bellas Artes. También la presencia de Colombia y la Universidad de Sinaloa brindaron espacios de diálogo sobre el trabajo actoral.

Los alumnos de danza, con la coreografía Sombreros, de Adriana Castaños, realizan presentaciones dentro del campus, otros viajan a la Unidad de Noga-

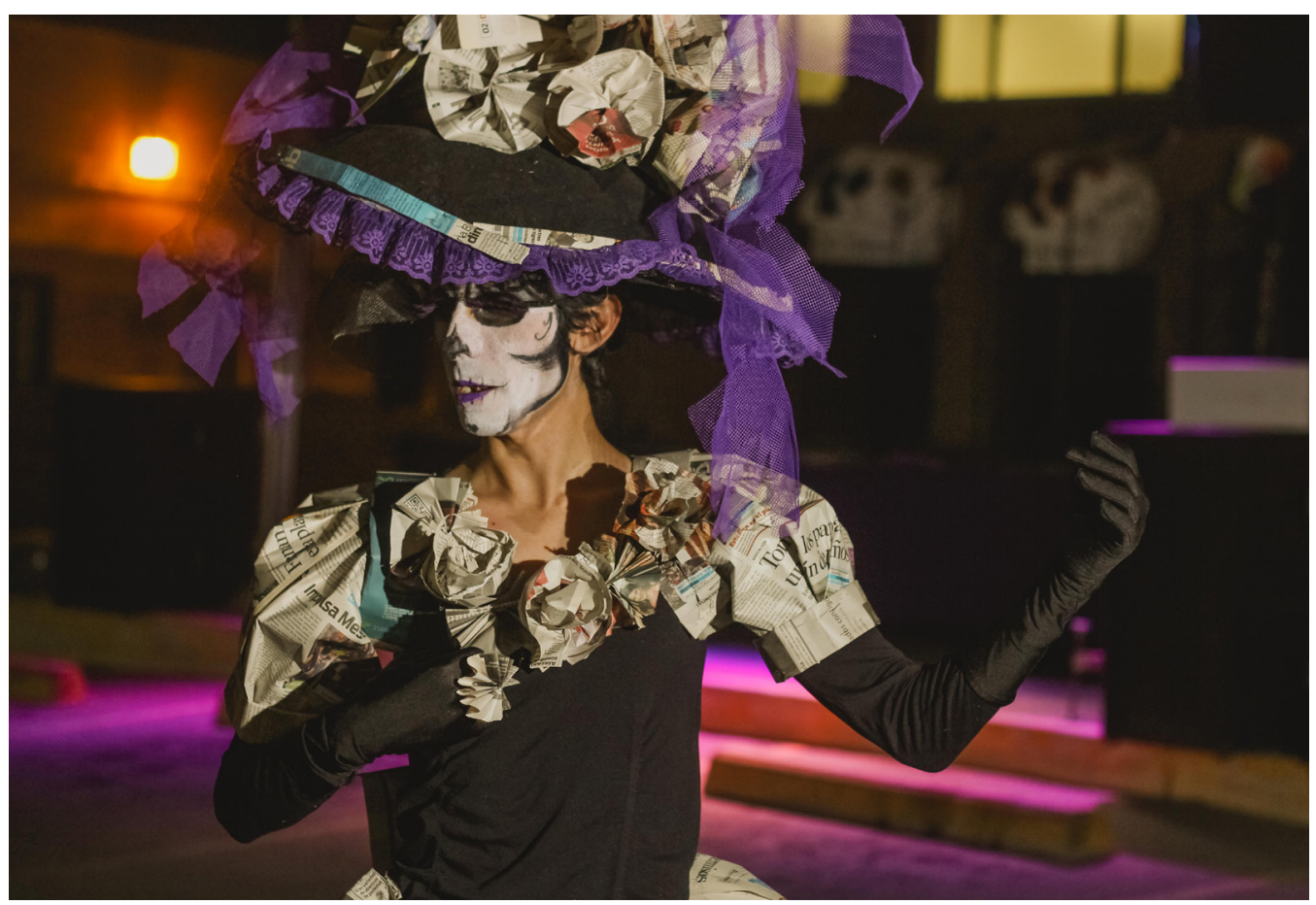


les o presentan sus avances en el Teatro Emiliana de Zubeldía.

Los jóvenes de Plásticas, organizaron el Festival de la Catrina, que incluye la participación de alumnos de distintas Licenciaturas. La procesión de muertos, que cada año presenta

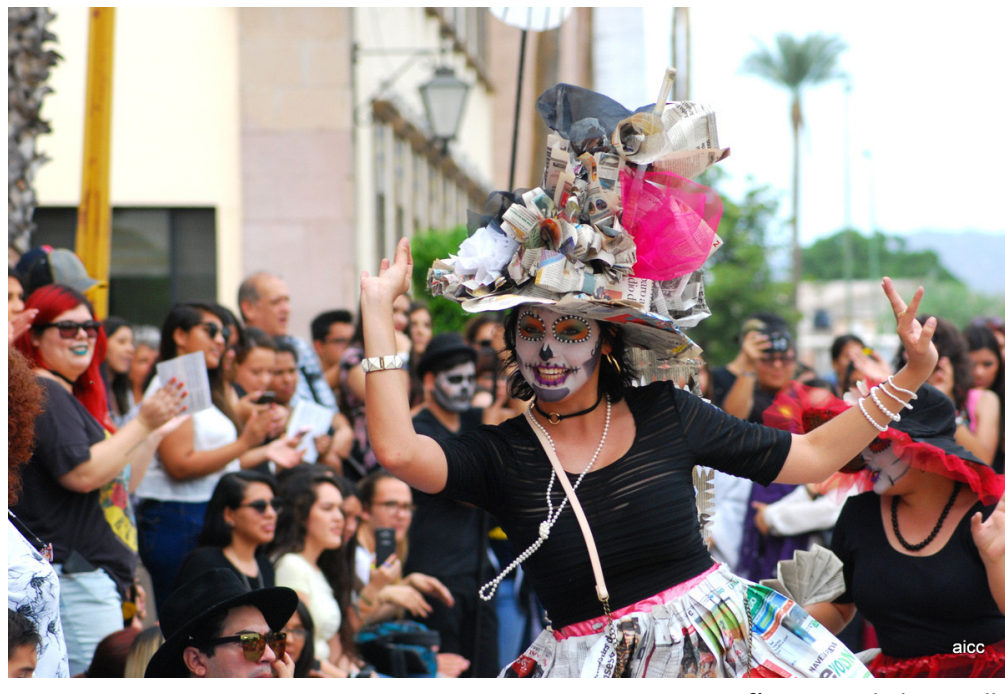

Fotografia: Ana Isabel Campillo cuadros escénicos con los motivos sociales, políticos y económicos de nuestro entorno, fue como siempre, un punto clave que une a Bellas Artes con toda la Universidad.

La Maestra Teresa Rodríguez compartió su saber en el taller de canto, que organiza la escuela de música y el resultado fue un destacado concierto en el que pudimos ver el avance de los chicos que estudian así como las interpretaciones de varios egresados.

El Departamento de Bellas Artes está presente en la vida cultural de nuestra Alma Mater, y como antes y como siempre, es un punto que debe permanecer vigente en cualquier administración. Un pueblo sin cultura es un pueblo sin alma.

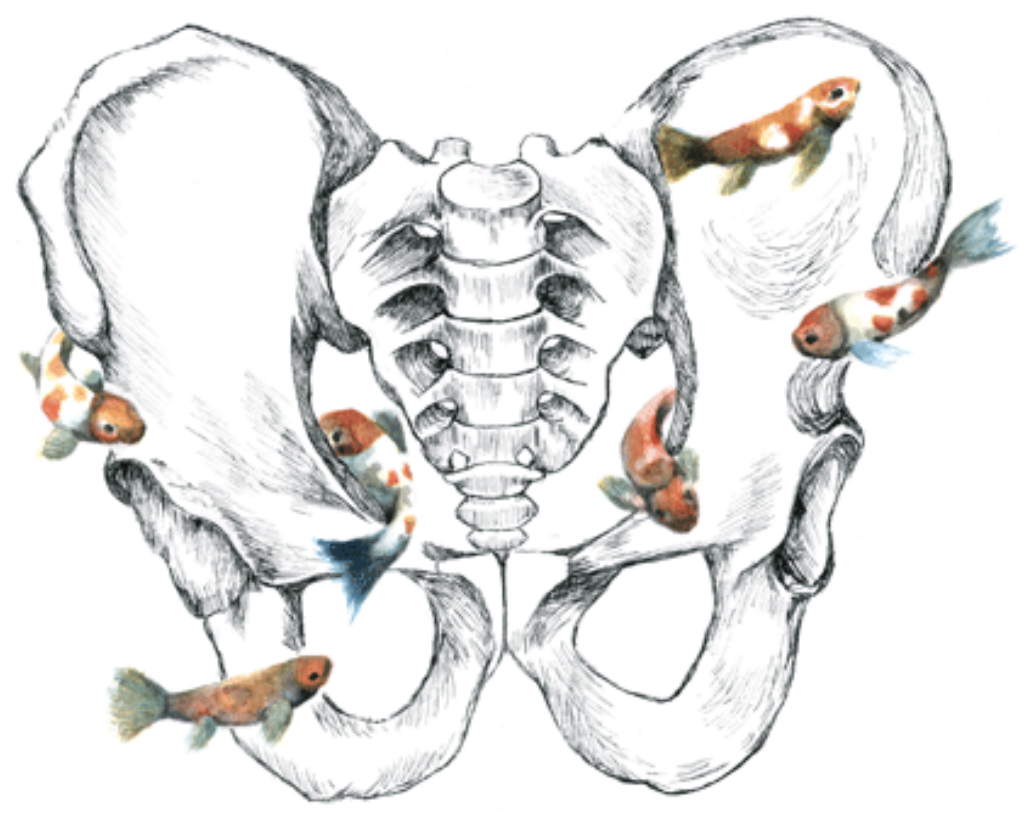

